\title{
ヤマハッカ属化合物の抗菌活性について
}

\author{
磯 部 孝 彦, ${ }^{*}, a$ 長田久美子 $b$
}

\section{The Study on the Antibacterial Activity of Compounds from the Isodon Species}

\author{
Takahiko ISOBE ${ }^{*}, a$ and Kumiko NAGATA ${ }^{b}$ \\ ${ }^{a}$ Department of Chemistry, Liberal Arts Center, Hyogo University of Health Sciences, 1-3-6 Minatojima, \\ Chuo-ku, Kobe 650-8530, Japan, and ${ }^{b}$ Department of Food and Nutrition, Faculty of Human Life \\ Sciences, Senri Kinran University, 5-25-1, Fujishirodai, Suita, Osaka 565-0873, Japan
}

(Received July 27, 2009; Accepted November 16, 2009)

\begin{abstract}
We investigated antibacterial activities of ten compounds from Isodon species against five strains of Escherichia coli, Staphylococcus epidermidis, Serratia marcescens, Streptococcus mutans, and Helicobacter pylori. The compounds with the MIC values of $25 \mu \mathrm{g} / \mathrm{ml}$ were isodocarpin against Sta. epidermidis, Str. mutans, and H. pylori, nodosin against Sta. epidermidis and Str. mutans, oridonin against Ser. marcescens, and pedalitin against $H$. pylori.
\end{abstract}

Key words_—antibiotic activity; Isodon; isodocarpin; Rabdosia; oridonin

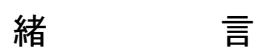

前報ではブラジル産シソ科植物成分の生物活性作 用について報告した. ${ }^{1)}$ 今回は，シソ科ヤマハッカ 属（中国名；唇形科香茶菜属）（Isodon あるいは Rabdosia）の抗菌活性試験について報告する。こ の属の植物は東南アジアに自生し，その中のいくつ かは生薬として使用されている. ${ }^{2-4)}$ 例えば，この 中のヒキオコシ（Isodon japonicus HARA）は健胃 剂，㿉の病，胃痤攣などに効くとされている. ${ }^{5)}$ 現 在，この属から ent-kaurane 型を主とする 850 種以 上の diterpene が単離され，その構造が解明されて いる．また，それらの化合物の中のいくつかについ ては，抗菌活性や抗腫瘍活性を含む種々の生物活性 評価が実施されている.

現在までに，この属のIsodon japonicus（ヒキオ コシ), ${ }^{8,9)}$ I. japonicus var. glaucocalyx (蘭葶香茶 菜), ${ }^{10,11)}$ I. trichocarpus（クロバナヒキオコシ), ${ }^{12)}$ Rabdosia amethysthoides (香茶菜) ${ }^{13)}$ R. eriocalyx (毛葶香茶菜), ${ }^{14)} R$. excisa (亀葉草) ${ }^{15)} R$. inflexa (内折香茶菜) , ${ }^{16,17)} R$. phyllopodia (柄葉香茶菜), ${ }^{18)}$ $R$. rubescens (冬凌草), ${ }^{19,20)}$ 及び $R$. serra（渓黄

$a$ 兵庫医療大学共通教育センター化学, $b$ 千里金蘭大学 生活科学部食物栄養学科

*e-mail: isobe-t@huhs.ac.jp
草) ${ }^{21,22)}$ の各植物全草について, 水あるいは alcohol 抽出物の抗菌活性が報告されている.

しかし，ヤマハッカ属から得られた化合物につい ての抗菌活性試験の報告事例は多いとは言えない. そこで，今回，日本産ヤマハッカ属成分の数種につ いて抗菌活性を調べた。実験に供した化合物は同属 植物より単離した 9 種類の diterpene と 1 種類の flavone である. Diterpene は $(\mathbf{1}-4),(5,6),(7)$, $(\mathbf{8}, 9)$ の 4 つのタイプに分類される ent-kaurane 型 化合物である。これらの化合物の中で, enmein (1),$^{23-27)}$ oridonin (5), 25-27) nodosin (3), 25,26) isodonal (7), 25) dihydroenmein (2), 27) pedalitin (10) ${ }^{28)}$ については，いくつかの細菌に対する抗菌活 性が既に報告されている. 今回行つた 5 種の細菌, すなわち，大腸菌（Escherichia coli），表皮ブドウ 球菌（Staphylococcus epidermidis），セラチア菌 (Serratia marcescens), 虫歯菌 (Streptococcus mutans), 及び，ピロリ菌 (Helicobacter pylori) と, 10 種の化合物群の組み合わせにおいていくつかの 新知見が得られた。 なお大腸菌以外では，今までに， enmein（1）の虫歯菌に対する, ${ }^{29)}$ enmein（1）及び oridonin（5）のピロリ菌に対する抗菌活性が報告 されている. ${ }^{30)}$ 
方法

抗菌活性評価に使用した菌種は, 独立行政法人理 化学研究所バイオリソースセンター微生物材料開発 室（埼玉県和光市広沢 2-1）から入手した。 菌株は Escherichia coli $\mathrm{K}-12$, Staphylococcus epidermidis ATCC 14990, Serratia marcescens ATCC 13880, Streptococcus mutans RIMD 3125001, 及び Helicobacter pylori ATCC 43504 である.

使用した enmein (1), isodonal (7), pedalitin (10) は, ヒキオコシ (Isodon japonicus HARA) ${ }^{25,31)}$ から 単離し構造決定した化合物である. 同様に, nodo$\sin (3)$, isodocarpin (4) はアキチョウジ（I. longitubus KUDO) ${ }^{32)}$ から, oridonin (5) はミヤマヒキ オコシ (I. shikokianus HARA) ${ }^{33)}$ から, kamebakaurin（8), kamebanin（9）はタイリンヤマハッカ (I. umbrosus var. excisinflexus (Nakai) AsANO) ${ }^{34)}$ か ら得られた化合物を使用した。 dihydroenmein (2), dihydrooridonin（6) については，それぞれ enmein （1）と oridonin（5）を水素による接触還元反応に より得た. 使用した化合物の中で, 筆者が構造決定 した化合物以外の化合物は, 当該文献記載の著者よ り提供されたものである.

1. 抗菌試験の方法 抗菌試験の培地, 菌の培 養, 酸素濃度の調整などは, 文献記載の方法に準じ た。 ${ }^{35,36)}$ 秤量した試料は DMSO 溶液とした後,

PBS (リン酸緩衝化生理食塩水, phosphate buffered saline）で希釈し， $10 \mu \mathrm{g} / \mathrm{ml}$ 溶液として活性試験に 用いた. 対照として無試料のものと比較した. 菌の
増殖を阻害する最小濃度である MIC は $90 \%$ 以上の 菌の増殖阻害をもって決定した.

\section{結果と考察}

Escherichia coli（グラム陰性菌, 大腸菌), Staphylococcus epidermidis（グラム陽性菌, 表皮ブド ウ球菌), Serratia marcescens (グラム陰性菌, 夕 ンパク質分解酵素産生), Streptococcus mutans (グラム陽性菌, 虫歯菌), 及び Helicobacter pylori （グラム陰性菌，胃潰瘍の菌）に対する化合物（110）の抗菌活性の結果を Table 1 に, 各化合物の構 造式を Fig. 1 に示した. Table 1 から, E. coli は oridonin にごく弱い活性（ $\mathrm{IC}_{90}: 100 \mu \mathrm{g} / \mathrm{ml} ）$ が認め られ，同様に Ser. marcescens に対して oridonin の みが弱い活性 $(25 \mu \mathrm{g} / \mathrm{ml})$ を示した. Sta. epidermidis, Str. mutans 及び H. pylori に対して, enmein (1), nodosin (3), isodocarpin (4), oridonin (5) の 4 種は, 弱いか, やや弱い活性 $(25-50 \mu \mathrm{g} / \mathrm{ml})$ を示 した. 中でも, isodocarpin（4）はこれらの中で, 比較的活性が強い $(25 \mu \mathrm{g} / \mathrm{ml})$ ことがわかった。 ま た, enmein (1), oridonin (5) の H. pyloriに対する 抗菌活性值 $(50 \mu \mathrm{g} / \mathrm{ml})$ を文献値と比較すると, 培 地の条件などが異なるため正確ではないが，デー夕 からほぼ同程度と考えられる. ${ }^{30)}$ 今回, 初めて抗菌 活性を調べた isodocarpin（4）は，Sta. epidermidis, Str. mutans とH. pyloriに対してやや弱い活性（25 $\mu \mathrm{g} / \mathrm{ml})$ が認められた。

Diterpene の中で抗菌活性がある化合物は, 16en-15-one 構造を持つことが既に指摘されており, ${ }^{37)}$

Table 1. Inhibitory Concentration $\left[\mathrm{IC}_{90}(\mu \mathrm{g} / \mathrm{ml})\right]$ by Compounds against Five Bacteria

\begin{tabular}{|c|c|c|c|c|c|c|}
\hline & & \multicolumn{2}{|c|}{ Gram positive } & \multicolumn{3}{|c|}{ Gram negative } \\
\hline & & $\begin{array}{l}\text { Staphylococcus } \\
\text { epidermidis }\end{array}$ & $\begin{array}{l}\text { Streptococcus } \\
\text { mutans }\end{array}$ & $\begin{array}{c}\text { Escherichia } \\
\text { coli }\end{array}$ & $\begin{array}{c}\text { Serratia } \\
\text { marcescens }\end{array}$ & $\begin{array}{c}\text { Helicobacter } \\
\text { pylori }\end{array}$ \\
\hline (1) & Enmein & 50 & 50 & $>100$ & $>100$ & 50 \\
\hline (2) & Dihydroenmein & $>100$ & $>100$ & $>100$ & $>100$ & $>100$ \\
\hline (3) & Nodosin & 25 & 25 & $>100$ & $>100$ & 50 \\
\hline (4) & Isodocarpin & 25 & 25 & $>100$ & $>100$ & 25 \\
\hline (5) & Oridonin & 50 & 50 & 100 & 25 & 50 \\
\hline (6) & Dihydrooridonin & $>100$ & $>100$ & $>100$ & $>100$ & $>100$ \\
\hline (7) & Isodonal & $>100$ & $>100$ & $>100$ & $>100$ & $>100$ \\
\hline (8) & Kamebakaurin & $>100$ & $>100$ & $>100$ & $>100$ & $>100$ \\
\hline (9) & Kamebanin & $>100$ & $>100$ & $>100$ & $>100$ & $>100$ \\
\hline (10) & Pedalitin & $>100$ & $>100$ & $>100$ & $>100$ & 25 \\
\hline
\end{tabular}

$\mathrm{IC}_{90}$ was defined as the inhibitory concentration that produced $90 \%$ growth inhibition. 


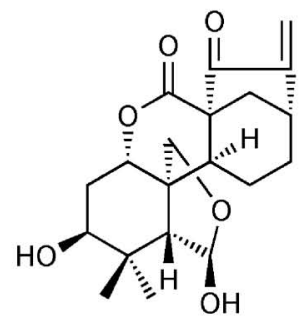

(1) Enmein

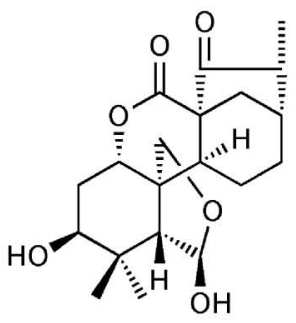

(2) Dihydroenmein

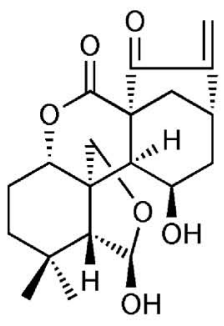

(3) Nodosin

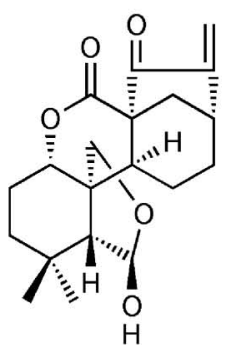

(4) Isodocarpin

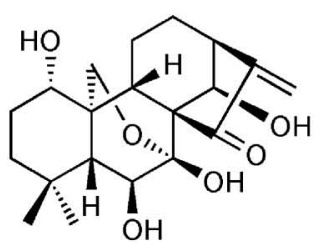

(5) Oridonin

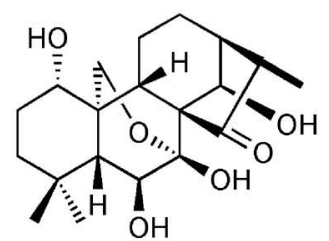

(6) Dihydrooridonin

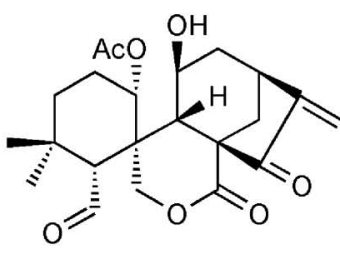

(7) Isodonal

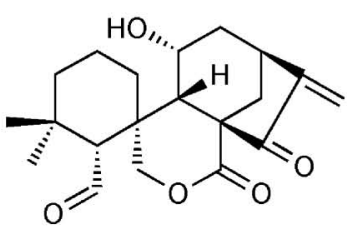

Trichorabdal A

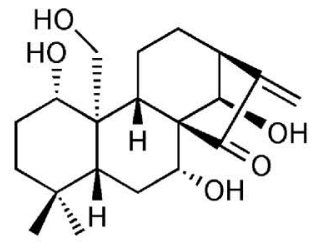

(8) Kamebakaurin

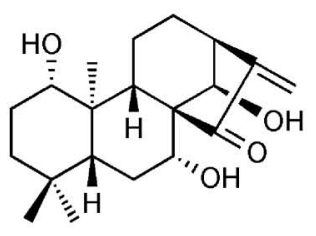

(9) Kamebanin<smiles>COc1cc2oc(-c3ccc(O)c(O)c3)cc(=O)c2c(O)c1O</smiles>

(10) Pedalitin

Fig. 1. Chemical Structures of Diterpenoids (1-9) and Flavonoid (10)

今回 dihydro 体（2)，(6）に活性がなかったことと 一致している. しかし，16-en-15-one 構造を持って いても分子全体の構造によって活性が現れないこと があり, isodonal (7), kamebakaurin (8), kamebanin (9) がその例となることが判明した。また, kamebakaurin（8) や kamebanin（9）が活性を示さ なかったことは，その構造の中に acetal 構造が存在 しないことも一要因と考えられる. 今回, H. pylori に活性があった diterpene は ent-kaurane 構造を持 $つ$ 6,20-epoxy-6-acetal 型の oridonin (5) や 6,7-seco1,7-olide 型の enmein (1), nodosin (3), isodocarpin (4)であった。文献では seco-20,7-olide 型の trichorabdal A において活性があったと報告されている が, 30) 今回の実験では, 同じタイプの isodonal (7) にその活性は認められなかった。活性には分子全体 の複雑な要素が絡んでいるので, これら化合物の構 造活性相関を充分に明らかにはできないが，少なく とも，細菌との結合のためには，16-en-15-one, oxygenated 20 position, acetal-structure など酸素官
能基の位置や構造が重要である可能性が高いことが わかった。 また，今回の実験で，isodocarpin (4) が 3 種の細菌に対して抗菌活性を示した。このこと は，同じ型の enmein（1） や nodosin（3）のように acetal 以外の hydroxy 基が存在していない化合物に も，活性が認められたことを考慮すると，活性構造 相関を考える上で重要な知見である.

また，今回，抗酸化作用がある flavone の pedalitin (10) ${ }^{38)}$ についても抗菌活性を検討したところ, 以前の報告と同様, H. pylori に活性が認められ た. ${ }^{28)}$

\section{REFERENCES}

1) Isobe T., Doe M., Morimoto Y., Nagata K., Masuoka N., Ohsaki A., Yakugaku Zasshi, 127, 389-395 (2007).

2) Li H.-W., J. Arnold Arbor Harv. Univ., 69, 289-400 (1988).

3) Hara H., J. Jpn. Bot., 47, 193-203 (1972).

4) Hara H., J. Jpn. Bot., 60, 230-237 (1985). 
5) Okuda T., "Encyclopedia of Natural Medicine," Hirokawa Shoten, Tokyo, 1986, p. 343.

6) Sun H.-D., Xu Y.-L., Jiang B., "Diterpenoids from Isodon species," Sience Press, Beijing, 2001.

7) Sun H.-D., Huang S.-X., Han Q.-B., Nat. Prod. Rep., 23, 673-698 (2006) .

8) Tanabe S., Nishikawa H., Nippon Saikingaku Zasshi, 9, 475-477 (1954).

9) An B.-J., Park J.-M., Bae H.-J., Pyun J.-R., Song M.-A., J. Korean Soc. Appl. Biol. Chem., 49, 129-134 (2006).

10) Jin Z.-M., Sha W., Hu X.-Y., Guangxi Sci., 14, 160-162 (2007).

11) Vichkanova S. A., Rubinchik M. A., Farmakol. Toksikol., 29, 605-609 (1966).

12) Osawa K., Yasuda H., Maruyama T., Morita H., Takeya K., Itokawa H., Okuda K., Chem. Pharm. Bull., 42, 922-925 (1994).

13) Zhang X.-H., Clin. Med. Chin., 3, 13-14 (1982).

14) Shu Y., Wang M.-D., Song J.-P., Wang Z.K., J. Yunnan Univ. Tradit. Chin. Med., 18, 9 -12 (1995).

15) Wang Q., Dai H., Zhu X.-H., Wang L., Pharm. J. Chin. People's Liberation Army, 22, 428-431 (2006).

16) Dong H.-X., Zhang C.-F., Liao Y.-M., Zhang X.-P., Xin Q., Li J.-M., Liu X.-Z., Tian F.-L., J. Jining Med. Coll., 21, 27-29 (1998).

17) Zhang C.-F., Li Y.-L., Jia Z.-S., Chin. J. Hospital Pharm., 20, 400-402 (2000).

18) Yang Y.-B., Zhu D.-Y., Chin. J. Modern Appl. Pharm., 12, 25-26 (1995).

19) Duan X.-Y., Wang Y.-H., Henan J. Tradit. Chin. Med. Pharm., 12, 38-40 (1997).

20) Song F.-J., Wu S.-Y., Liang J.-J., J. SouthCentral Univ. for Nationalities (Nat. Sci. Edi.), 23, 9-11 (2004).

21) Liang C.-N., Duan Z.-F., Fu L., Food Sci. Technol., 28, 58-60 (2003).

22) Zhan Y., Ning Z.-X., Sci. Technol. Food Ind.,
24, 61-63 (2003).

23) Ohyama A., Furumoto Y., Chikugo S., Ishiga A., Takami Y., Nomura M., Yokota S., Liao F.-S., Awai T., Fuwa A., Yamada M., Ueda Y., Ishii N., Kurimura T., Tanaka S., Kobe Ika Daigaku Kiyo, 13, 253-257 (1958).

24) Arai T., Koyama Y., Suenaga T., Morita T., J. Antibiot. Ser. A, 16, 132-138 (1963).

25) Kubo I., Kamikawa T., Kubota T., Tetrahedron, 30, 615-622 (1974).

26) Kakinuma K., Okada Y., Ikekawa N., Kada T., Nomoto M., Agric. Biol. Chem., 48, 16471648 (1984).

27) Fujita E., Nagao Y., Kaneko K., Nakazawa S., Kuroda H., Chem. Pharm. Bull., 24, 21182127 (1976).

28) Isobe T., Doe M., Morimoto Y., Nagata K., Ohsaki A., Biol. Pharm. Bull., 29, 1039-1041 (2006).

29) Shimada K., Kudo S., Hayashi K., Akutagawa H., Ito K., Murai S., Nippon Shishubyo Gakkai Kaishi, 36, 586-591 (1994).

30) Kadota S., Basnet P., Ishii E., Tamura T., Namba T., Zentralbl. Bakteriol., 286, 63-67 (1997).

31) Isobe T., Noda Y., Kubota T., Nippon Kagaku Kaishi, 1513-1515 (1985).

32) Isobe T., Kamikawa T., Kubota T., Nippon Kagaku Kaishi, 2143-2148 (1972).

33) Kubota T., Kubo I., Bull. Chem. Soc. Jpn., 42, 1778 (1969)

34) Isobe T., Noda Y., Shibata K., Nippon Kagaku Kaishi, 493-496 (1994).

35) Nagata K., Sone N., Tamura T., Antimicrob. Agents Chemother., 45, 1522-1527 (2001).

36) Nagata K., Wada Y., Tamura T., Koyama J., Hirai K., Nippon Kagaku Ryoho Gakkai Zasshi, 47, 9-14 (1999).

37) Kubo I., Taniguchi M., Satomura Y., Kubota T., Agric. Biol. Chem., 38, 1261-1262 (1974).

38) Masuoka N., Isobe T., Kubo I., Phytother. Res., 20, 206-213 (2006). 